\title{
INDIOS E MILITARES NO SÉCULO XX: A INVISIBILIDADE DO CAOS HUMANO NAS FRONTEIRAS
}

\author{
Maria Geralda Almeida Moreira \\ Mestrte em História pela Universidade Federal de Goiáis. Docente do Curso de \\ História da Universidade Estadual de Goiás. \\ geraldamoreira44@gmail.com
}

resumo: A política indigenista adotada durante a Ditadura Militar visava, dentre outros objetivos, à ocupação da Amazônia por meio da construção de estradas, de hidrelétricas e do incentivo à migração para regiões consideradas, até então, como "vazios demográficos". Essa política foi responsável pelo genocídio de etnias inteiras e pelo processo que buscava a transformação de índios em "não-índios", a desindianização. Tais práticas mantiveram-se nos subterrâneos, não conseguiram extrapolar as fronteiras étnicas e permaneceram na memória dos sobreviventes desses massacres indígenas. 0 objetivo aqui consiste, por um lado, em analisar as ações empreendidas pelo Estado contra os indígenas, por considerá-los "subversivos", e, por outro, em evidenciar a ação de resistência realizada pelos indígenas frente a essa política genocida. A pesquisa foi realizada, primordialmente, com base na documentação produzida pelo Comitê Estadual da Verdade do Amazonas e pela Comissão Nacional da Verdade.

Palauras-chave: Indígenas. Ditadura. Genocídio. Resistência. abstract: The Indigenous policy adopted during the Military Dictatorship aimed, among other objectives, the occupation of the Amazon region by the construction of roads, hydropower plants and the incentive for migration to the areas considered hitherto as "demographic vacuums". This policy was responsible for the genocide of entire ethnicities and the process of transformation of the indigenous into "not indigenous". These practices have remained underground, they did not extrapolate the ethnic boundaries and continued in the memory of the survivors of these indigenous massacres. The objective consists, on the one hand, analyses the actions undertaken by the State against the indigenous, considering them "subversives", and on the other hand, to evidence the action of resistance performed by the indigenous facing this genocide policy. The research was realized, primarily, on the basis of documentation produced by the State Committee of Truth from Amazon and the National Commission of Truth.

Key-words: Indigenous people. Dictatorship. Genocide. Resistance. 


\section{introdução}

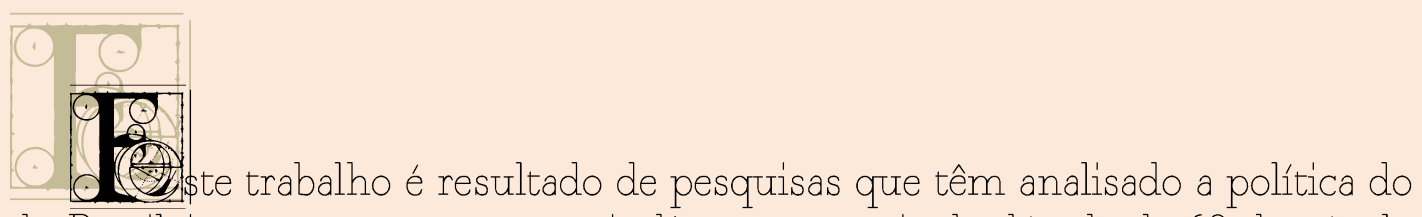
Estado Brasileiro para com os povos indígenas a partir da década de 60 do século XX. Nesse sentido, constitui-se como objetivo abordar a invisibilidade do genocídio cometido contra os indígenas no Brasil, especificamente, contra os Waimiri-Atroari, no período compreendido como Ditadura Militar. Constitui, ainda, em objetivo desse texto evidenciar e discutir a ação de resistência dos indígenas, contribuindo, assim, para a compreensão histórica desses fatos ao evidenciar não somente as ações dos grupos dominantes, mas dos subalternos ao expor suas formas de resistência e organização. Como afirma Guha1, a ação dos subalternos é comumente descaracterizada e deslegitimada, e, como consequência desse processo, as ações desses grupos são observadas como desprovidas de qualquer consciência. Evidenciar o contrário torna-se essencial para romper com esses espaços-comuns e legitimar o movimento de resistência realizado pelos povos indígenas do Brasil desde a chegada dos portugueses.

A política indigenista adotada pelo governo militar estava orientada para atender e contribuir com os ideais de segurança e integração nacional. A integração da Amazônía, considerada até então como "vazio demográfico", era objetivo primordial. Essa política foi responsável pelo genocídio de etnias inteiras e por um processo que buscava a desindianização ${ }^{2}$ de outras. A violência sofrida pelos

1 GUHA, Renajit. Las voces de La Historia y otros estúdios subalternos. Barcelona: Crítica, 2002.

20 termo desindianização é tomado aqui como o processo de indígenas tornarem-se “(...) não-índios, os índios que não eram mais índios, isto é, aqueles indivíduos indígenas que "já" não apresentassem "mais" os estigmas de indianidade estimados necessários para o reconhecimento de seu regime especial de cidadania" empreendido pelo governo militar. Todavia, na análise de Castro, tal processo impulsionou e projetou os indígenas, tornando-os mais visíveis e organizados. CASTRO, Eduardo Viveiros de. "No Brasil, todo mundo é índio, exceto quem não é”. Povos Indígenas do Brasil. ISA. 2006. Disponível em: https://pib.socioambiental.org/files/file/PIB_institucional/No_Brasil_todo_mundo_\%C3\%A9_\%C3\%ADndio .pdf. Acesso em: 16 de abril de 2017. As 18h07min. 


\section{7}

indígenas nesse período foi mantida em silêncio por décadas, não conseguiu extrapolar as fronteiras étnicas, mantendo-se nos subterrâneos, nas memórias dos sobreviventes dos massacres.

A invisibilidade do caos humano nas fronteiras ${ }^{3}$ só era interrompida por raras vozes que ousavam falar de vítimas indígenas da ditadura. Vítimas que não foram contabilizadas nos registros oficiais, nem constam nas narrativas históricas construídas pelos sujeitos que direta ou indiretamente foram vítimas dessa violência. As vozes indígenas começam a emergir dos escombros no início do século XXI, as memórias subterrâneas encontram escuta e ecoam. De norte a sul, de leste a oeste, registros, narrativas, lugares de memórias começam a corroborar a violência vivida pelos indígenas nesse período sombrio de nossa história.

\section{compreendendo as fontes}

$\mathrm{Na}$ tessitura da narrativa acerca da violência perpetrada contra os povos indígenas e suas formas de resistência empregamos diferentes fontes escritas. De forma geral, são fontes secundárias, pois resultam do olhar do não-índio acerca dos fatos. As fontes analisadas compõem-se de documentos oficiais, Primeiro Relatório do Comitê Estadual da Verdade do Amazonas: Regional Amazonas sobre o Genocídio do Povo Waimiri-Atroari e o texto Víolação dos Díreitos Humanos dos Povos Indígenas - eixos temáticos, volume II, texto 5, produzido pela Comissão Nacional da Verdade. Os dois documentos/fontes podem ser considerados uma segunda leitura do fato, pois, como observa Geertz ${ }^{4}$ apenas o nativo faz a primeira leitura, os estudiosos dos fenômenos humanos têm acesso a essas realidades apenas de forma marginal. Partindo da perspectiva de Geertz ${ }^{5}$ o que temos em mãos são leituras secundárias, construídas e permeadas por olhares externos, o que torna ainda mais desafiadora a tarefa de encontrar os vestígios da ação desses grupos subalternizados 6 .

Com o fim da Ditadura Militar, a FUNAI (Fundação Nacional do Índio)inicia uma nova fase de ação junto aos indígenas que consistia em atender às necessidades colocadas por eles diante de diagnósticos realizados por grupos de trabalhos. Nesse

\footnotetext{
${ }^{3} 0$ termo fronteira foi empregado aqui não para se referir ao espaço físico, mas como demarcador das diferenças, de uma condição limite vivenciada nesse contexto pelos diferentes segmentos sociais envolvidos nesse conflito.
}

${ }^{4}$ GEERTZ, C. A Interpretação das Culturas. Rio de Janeiro: LTC, 2008.

${ }^{5}$ Idem.

${ }^{6}$ GUHA, Renajit. La muerte de Chandra. História y Grafia. México: Universidad Iberoamericana, n. 12, 1999. 
contexto, é criado o Grupo de Estudos sobre os Waimiri-Atroari. Egydio e sua esposa Doroty Schwade foram convidados a desenvolver um projeto de alfabetização junto a esse grupo indígena. Sobre a inserção do casal nesse projeto, Egydio Schwade afirma:

Naquele momento eu era então Secretário Executivo do CIMI Nacional, cujo trabalho continuamos até 1980. Naquele ano viemos, a convite de Dom Jorge Marskell, bispo da Prelazia de Itacoatiara/AM, assumir a Pastoral Indígena desta Prelazia, em especial para iniciar um trabalho junto ao povo Waimiri-Atroari. A tarefa foi muito difícil por conta do bloqueio, da perseguição e da difamação perpetrada por agentes da Ditadura Militar e de gananciosos que promoviam o extermínio daquele povo para se apossar e expropriar o território. Doroti e eu nos localizamos primeiro na sede da Prelazia, em Itacoatiara, inserindo-nos na Pastoral, fazendo levantamentos no entorno da área WaimiriAtroari e fazendo contatos com algumas aldeias, mesmo estando proíbidos pelos Ditadores. Para permanecer mais próximos da área indígena estabelecemo-nos, no inicio de 1984 no recém-criado município de Presidente Figueiredo. Com o fim da Ditadura Militar fomos convidados pelos índios e autorizados pela EUNAI a participar da vida em suas aldeias, iniciando o primeiro trabalho de alfabetização em sua língua materna. Pela primeira vez o povo Waimiri-Atroari ou Kiña, como se autodenominam, começou a revelar o que lhe aconteceu durante a Ditadura Militar?

Primeiro Relatório do Comitê Estadual da Verdade do Amazonas: Regional Amazonas sobre o Genocídio do Povo Waimiri-Atroarl compõe-se de informações colhidas pelo casal Egydio Schwade e Doroti Alice M. Schwade junto aos índios Waimiri-Atroari, no período entre 1985 e 1986, principalmente através de textos e desenhos espontâneos produzidos pelos próprios índios por ocasião do processo de alfabetização inspirado no método de Paulo Freire desenvolvido pelo casal. Nesse processo, as informações foram colhidas de forma espontânea, poìs, o objetivo não era o registro dessa história, mas a alfabetização. De acordo com

${ }^{7}$ SCHWADE, Egydio. Doroti Alice Muller Schwade: Recordação no seu terceiro ano de falecimento. Urubui. Disponível em: http://urubui.blogspot.com.br/2013/12/doroti-alice-muller-schwade-recordacao.html. Acesso em: 15 de abril de 2017.

8 PRIMEIRO Relatório do Comitê Estadual da Verdade: o Genocídio do Povo Waimiri-Atroari. Manaus, 2012. 
Schawade9, no método adotado os índios que participavam do processo de alfabetização produziam desenhos elou frases, fora do horário de aula, e, no dia seguinte, durante as aulas tais produções eram discutidas. Foi a partir desse trabalho que grande parte dos registros foi adquirida.

A emergência dessas memórias nos leva a inferir que estas eram incômodas, sobrepondo-se a outras que os índios participantes do projeto poderiam usar para construir seus desenhos elou textos, como a descrição de uma caçada ou pescaria, por exemplo.

Entretanto, após um ano de execução, o projeto foi abortado, pois colocava em xeque interesses empresariais iniciados durante a Ditadura, sendo o casal Schwade expulso da terra indígena Waimiri-Atroari, em dezembro de 1986.

○ controle das informações acerca dos Waimiri-Atroari se amplia no fím da década de 1980, com Romero Jucá na direção da FUNAI, com isso, após a expulsão do casal Schawade, o pesquisador da Unicamp, Márcio Sílva, foí impedído de continuar suas pesquisas com o grupo. Em 1989, o antropólogo Stephen Baines, que realizava pesquisa com a etnia desde 1982, também foi expulso da área pela FUNAI, sendo impedido de continuar suas pesquisas com o grupo.

Segundo Baines ${ }^{10}$, a atuação da Frente de Atração Waimiri-Atroari $\left(\mathrm{FAWA}^{11}\right.$ ), com o apoio da FUNAI, fez com que os indígenas mudassem a interpretação de sua história anterior à FAWA. Por meio de um processo coordenado de reconstrução da memória social do grupo, a história de violação dos direitos humanos dos Waimiri-Atroari foi forçada a permanecer nos subterrâneos, nas memórias pessoais de quem vivenciou tais episódios, pois quando vinham à tona tornavam-se alvo de zombarias. Partindo da perspectiva de Pollak ${ }^{12}$, que concebe a memória como "(..) um fenômeno construído social e coletivamente e submetido a flutuações, transformações e mudanças constantes", essa "nova"

${ }^{9}$ COMITÊ, Estadual de Direito à Verdade, à Memória e à Justiça do Amazonas. A Ditadura Militar e o Genocídio do Povo Waimiri-Atroari. Relatório do Comitê Estadual de Direito à Memória e à Justiça do Amazonas. Campinas: Curt Nimuendajú, 2014.

10 BAINES, Stephen. Censuras e memórias da pacificação Waimiri-Atroari, Série Antropologia, Brasília, 1993 b, vol. 148, UnB.

. Imagens de lideranças indígenas e o Programa Waimiri-Atroari: índios e usinas hidrelétricas na Amazônia. Revista de Antropologia, São Paulo, USP, 2000, V. $43 \mathrm{n}^{\circ} 2$.

${ }^{11}$ A FAWA foi substituída em 1987 pelo Programa Waimiri-Atroari (FUNAI/ELETONORTE), que manteve a mesma política anterior.

12 POLLAK, M. Memória e Identidade Social. Estudos Históricos, Rio de Janeiro, vol. 5, n. ${ }^{\circ}$ 10, 1992 , p. 200-212. p. 201. 
memória social dos Waimiri-Atroari esvazia-se dessas lembranças, consideradas "besteiras de velhos" 13 .

No ambiente criado pela EAWA, os jovens Waimiri-Atroari raramente falavam sobre o passado. Quando o faziam, transformavam-no em zombarias como fazia a maioria dos funcionários da EAWA, esperando o mesmo comportamento do antropólogo. Quando tentei abordar assuntos relacionados ao passado, direta ou indiretamente, normalmente censuravam-nos com exclamações como "É besteira de velho!", "índio não sabe!" Frequentemente ridicularizavam os anciãos, arremedando as formas de discursos dos velhos lideres (...) os Waimiri-Atroari repudiavam assim seu passado ${ }^{14}$.

Desqualificando e reprimindo tais lembranças, ficava claro que estas memórias não cabiam na nova configuração sociocultural construída pela FAWA para o Waimiri-Atroari. As memórias acerca do passado foram mantidas nos subterrâneos, pois, ao final da construção da BR-174, implantou-se, junto aos Waimiri-Atroari, um amplo "(..) programa de controle de informação que mantém afastado, indigenistas, cientistas e jornalistas independentes" ${ }^{\text {"15 }}$, ou seja, qualquer pessoa que não esteja diretamente vinculada às ações empresariais desenvolvídas na região

Criada em 2012, a Comissão Nacional da Verdade contribuiu para "(...) trazer à luz do dia e apontar à sociedade que os índios no Brasil também foram atingidos pela violência do Estado" ${ }^{16}$ durante a Ditadura Militar. Os dois documentos resultantes da ação da Comissão Nacional da Verdade - O audiovisual da audiência da Comissão Nacional da Verdade com os Waimiri-Atroari, ocorrido no ano de 2013, e o texto Violação dos Díreitos Humanos dos Povos Indígenas: eixos temáticos, volume II, texto 5 - são produzidos no momento em que o Brasil se dispõe a analisar de forma mais abrangente esse passado, propondo reparações às pessoas e famílias vitimizadas por esse modelo de governo, e, no caso, dos Waimiri-Atroari, após uma intensa política de ressignificação de sua própria história, abordada por Stephen

${ }^{13}$ BAINES, 1993b, p. 5-6.

${ }^{14}$ Idem.

${ }^{15}$ COMITÊ ESTADUAL, 2015, p. 3.

16 COMISSÃO NACIONAL DA VERDADE. Violação dos Direitos Humanos dos Povos Indígenas. Textos temáticos. Volume II. Dezembro de 2014. Pp. 198- 256. p. 200. 
Grant Baines em textos como: Censuras e Memórias da Pacificação WaimiriAtroarl'17 e "Imagens de lideranças indígenas e o Programa Waimiri-Atroari: índios e usinas hidrelétricas na Amazônia ${ }^{18}$.

Outro fator que diferencia a primeira fonte, Primeiro Relatório do Comitê Estadual da Verdade do Amazonas: Regional Amazonas sobre o Genocídio do Povo Waimiri-Atroari, das demais é que os dados foram colhidos, ainda, na década de 80 do século XX, período em que a temática da violação dos direitos humanos dos indígenas pela ditadura não era preocupação do Estado e poucos estudiosos se aventuravam nessa ceara

Ao analisar os documentos construídos pela Comissão Nacional da Verdade, tais elementos precisam ser levados em consideração, uma vez que esse passado foi reprimido e maculado por anos junto aos Waimiri-Atroari, e indícios apontam que esse discurso passou a fazer parte do imaginário acerca desse passado.

documento final da Comissão Nacional da Verdade possui informações sobre diferentes grupos indígenas brasileiros impactados pelas ações do governo militar. No caso dos Waimiri-Atroari, a Comissão utiliza-se de dados do Comitê Regional do Amazonas

\section{a etnia waimiri-atroari e a política indigenista durante a ditadura militar}

A etnia Waimiri-Atroari, também é denominada pela literatura de Kija, Kiña, Uaimiry e Crichaná, todavia, nesse trabalho optamos pelo termo Waimiri-Atroari. Falante da língua Kinja Iara, que pertence à família linguística Karíb, esse povo que habita a região norte do país utiliza sua língua materna no cotidiano, sendo o português ensinado nas escolas e falado apenas nas relações que extrapolam as fronteiras de sua terra.

território habitado pelos Waimiri-Atroari em função do interesse do Estado e de empresários nas riquezas minerais e naturais da região tornou-se alvo de contínuas invasões e decretos-leis que reduziram sucessivamente o território disponível para essa etnia indígena. $\bigcirc$ primeiro decreto foi assinado em 1971, pelo então presidente Emílio Garrastazu Médici, em pleno período de construção da BR174, e cria a Reserva Indígena Waimiri-Atroari.

\footnotetext{
17 BAINES, 1993b.

${ }^{18}$ BAINES, 2000.
}

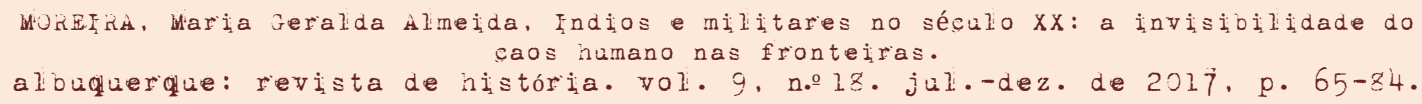


Decreto n 68.907 de 13 de julho de 1971, em seu artigo primeiro decreta: "Fica criada a Reserva Indígena Waimiri-Atroari, no Município de Airão, Estado do Amazonas, com a característica principal de área a eles reservada (..."1.19. Já no artigo segundo, o decreto define a área pertencente à reserva. Essa demarcação visava atender não aos indígenas, mas a interesses privados e não impediu que a BR em construção cortasse a área. A demarcação definiu como pertencendo aos indígenas uma parcela do território anteriormente usado por eles ${ }^{20}$

Em 1981, uma nova redefinição do território é realizada pelo Estado que a torna uma área "temporária" dos Waimiri-Atroari. De acordo com o artigo primeiro do Decreto n․ 86.630/81, "fica interditada, temporariamente, para fins de atração e pacificação dos grupos indígenas WAIMIRI e ATROARI21, a área de terras localizada nos Municípios de Novo Airão e Itapiranga, no Estado do Amazonas, e Caracaraí, no Território Federal de Roraima [...”22

Novamente, interesses particulares orientaram esse processo extremamente prejudicial aos índios ao reduzir e tornar a terra uma área "temporariamente" interditada. A idéia de território temporário foi usada na demarcação, pois se esperava que os índios, ao serem contatados, não necessitassem mais da área que poderia ser destinada a outros fins. Nesse processo foram deixadas fora dos limites demarcados áreas de interesses de mineradores e hidrelétricas. De acordo com dados do CIMI (Conselho Indigenista Missionário), os índios perderam 31\% do território original para a mineradora Parapanema com a redemarcação de 1981 e aproximadamente um quarto da área para a Hidrelétrica de Balbina com a redefinição de 198923.

É importante esclarecer aqui que o primeiro contato do grupo WaimiriAtroari com a sociedade envolvente teve como marco a expansão extrativista do século XVII que possuía, ainda, a finalidade de delimitar as fronteiras entre Espanha e Portugal. Entretanto, "(..) a história oficial do contato dos Waimiri-Atroari inicia-se no final do século XVIII (1884), com João Barbosa Rodrigues, que se intítula o primeiro pacificador desse povo" 24

${ }^{19}$ BRASIL. Decreto n. ${ }^{\circ}$ 68.907, de 13 de Julho de 1971.

${ }^{20}$ COMITÊ ESTADUAL, 2014.

21 Redação conforme consta no documento oficial.

22 BRASIL. Decreto n. ${ }^{\circ}$ 86.630, de 23 de novembro de 1981.

23 CEDI. Aconteceu. CIMI. 1987-1990.

${ }^{24}$ Disponível em: http://pib.socioambiental.org/pt/povo/waimiri-atroari/701. Acesso em: 19.03.2017. 
A partir do século XVIII, os Waimiri-Atroari presenciaram sistemáticas invasões de seu território ancestral empreendidas por diferentes frentes de expansão: do extrativismo à mineração; do agronegócio à ação estatal, e resistiram, ao longo de anos, ao processo de ocupação de suas terras ancestrais, o que lhes rendeu a fama de "ferozes" e "traiçoeiros".

Durante o período denominado Ditadura Militar, esse processo passou a ser empreendido pelo Estado Brasileiro por meio dos agentes responsáveis pelos projetos de desenvolvimento e segurança nacional, o que reduziu os WaimiriAtroari de aproximadamente 3.000 índios em 1972 para $332^{25}$ em 1983. Todavia, o que ocorre com esse grupo indígena não é uma exceção, mas regra que se estabelece a partir da instauração do regime milititar.

No final da década de 1960, a política indigenista é redefinida, tornando-se mais alinhada aos ideais de segurança nacional e aos interesses empresariais, o que se evidencia em ações sistemáticas de violência contra os indígenas. Segundo o relatório da CNV, o ano de 1968 "marca o início de uma política indigenista mais agressiva - inclusive com a criação dos presídios indígenas" (CNV, 2014, p. 203). É nesse período que tem início a construção da BR-174 (1967-1977), ligando Manaus (AM) a Boa Vista (RR), com a finalidade de viabilizar a entrada do capital interessado na exploração da região. O objetivo do governo militar era possibilititar o "(...) acesso às minas de Pitinga, seguidos dos interesses em fontes de energia e ocupação de uma área considerada pelo governo e empresários como "vazio demográfico"26.

Esse momento é marcado, ainda, pela veículação de denúncias de violação dos direitos dos indígenas, muitas dessas cometidas pelo órgão responsável pela implementação da política indigenista, o que levou à extinção do Serviço de Proteção ao Indio (SPI), em 1967, e à criação da FUNAI (Fundação Nacional do Indio). Com a criação da FUNAI, descortina-se uma nova fase da Política Indigenista, "a fase de subordinação mais direta à política de desenvolvimento e intervenção maciça na Amazônia (..." 27. Nesse sentido, a criação da FUNAI buscava atender aos interesses do governo militar de ajustar não somente a economia, mas também as instituições do país à nova fase do capitalismo, marcada mais pela associação ao sistema econômico internacional do que aos interesses dos índios.

${ }^{25}$ Dados de BAINES, Stephen G. Museu Emilio Goeldi. In: Comitê Estadual da Verdade do Amazonas. 2014, p. 26.

${ }^{26}$ COMITÊ ESTADUAL, 2014, p.52.

${ }^{27}$ ROCHA, Leandro Mendes. A Política Indigenista no Brasil: 1930-1967, UFG, Goiânia, 2003.p. 63. 
A substituição do SPI pela EUNAI não impede que o novo órgão indigenista tenha suas ações voltadas ao atendendimento à política do governo militar, principalmente no que se refere ao Plano de Integração Nacional e a sua investida sistematizada sobre a Amazônia, possibilitando assim a abertura da região ao capital internacional. A FUNAI nesse cenário visava "(...) integrar os índios, o mais rápido possível, à economia de mercado (...) e garantir que os mesmos não oferecessem obstáculos à ocupação e colonização da Amazônia" 28, justificando, inclusive, as mortes como "inevitáveis". A questão indígena se torna, portanto, de segurança nacional e a FUNAI "passa a ter uma assessoria influente de informação e segurança (ASI), com militares egressos de órgãos de informações (...) alguns de seus presidentes provêm diretamente de altos quadros desses serviços" ${ }^{29}$. Indígenas e seus apoiadores são taxados de "comunistas" e são perseguidos. $\bigcirc$ alinhamento da FUNAI aos interesses do Estado favorece a prática da violência contra os indígenas, justificada pela ideologia de segurança e integração nacional.

A implementação do Plano de Integração Nacional (PIN) demandou a pacificação de 30 etnias indígenas consideradas "arredias". Essa política incluía "pacifícação" e remoção desses grupos "em benefícios das estradas e da colonização pretendida" 30. $\bigcirc$ caso dos índios Parakanã, que foram removidos cinco (05) vezes no período de 1971 a 1977, levando a óbito 59\% da população do grupo por epidemias de gripe, poliomielite, malária e doenças venéreas, evidencia esse descaso com as populações indígenas e os abusos cometidos pelo Estado.

Em 1971, o médico Antônio Medeiros visitou a aldeia dos Parakanã e relatou a situação de calamidade encontrada. Segundo o médico, havia

um "quadro de promiscuidade" entre índios e gente de fora (...) 35 indias e dois agentes da EUNAI tinham doenças venéreas (...) oito crianças da aldeia nasceram cegas e pelos menos mais seis haviam morrido recentemente de disenteria (...). Cotrim revelou numa entrevista à imprensa brasileira que a infecção da tribo Parakanãn com doenças venéreas não foi um incidente isolado. Representava, segundo ele, parte de um quadro brutal que passara a caracterizar a situação de quase todas as tribos recentemente contactadas ao longo das estradas transamazônicas ${ }^{31}$

28 DAVIS, Shelton H. Vítimas do Milagre: o Estado e os Índios do Brasil. São Paulo: Zahar, 1978. p. 88. 29 COMISSÃO NACIONAL DA VERDADE, 2014, p. 205.

30 Idem, p. 203.

31 DAVIS, 1978, p. 94-95.

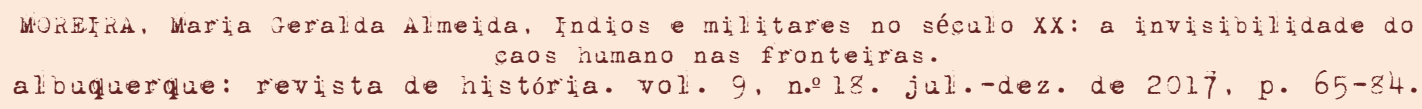


À medida que nos debruçamos sobre a documentação, as narrativas encontradas trazem à tona situações complexas de violação dos direitos humanos dos Povos Indígenas. Essas são, no entanto, memórias esquecidas, silenciadas pelas narrativas produzidas e publicizadas pela versão histórica oficial. São as memórias subterrâneas que, embora invisibilizadas, continuam a exercer influências nos processos de sociabilidades dentro e fora das fronteiras do grupo.

direito à memória é "um grande passo" em busca da superação da invisibilidade histórica imposta aos povos indígenas pela sociedade e pelo Estado. que não os reconhecem enquanto sujeitos de direitos. Nesse contexto, afirma Gagnebin que

(...) escrever a história dos vencidos exige a aquisiç̧ão de conhecimentos que não constam nos livros da história oficial. $\bigcirc$ historiador pretende fazer emergir as esperanças não realizadas [no] passado e inscrever em nosso presente seu apelo por um futuro diferente. Oesforço é não deixar essa memória escapar, mas zelar pela sua conservação, contribuir na reapropriação desse fragmento de história esquecido pela historiografia dominante ${ }^{32}$

Outro caso emblemático é o dos Avá-Canoeiro, grupo indígena do estado de Goiás. Esse grupo que historicamente resistiu ao processo colonizador na região do Cerrado acabou sendo capturado entre 1973 e 1974, após ação de extrema violência cometida pelos Agentes do Estado autoritário e, não bastasse isto, foi exposto ao público como um troféu. Segundo informações colhidas pela Comissão da Verdade, os Avá

(...) foram amarrados em fila indiana, sob a mira das armas de fogo e levados à força à sede da fazenda Canuanã, onde foram expostos à visitação pública dos moradores da região durante semanas colocados dentro de um quintal cercado de uma das casas da fazenda, como que em um zoológico (...) mulheres sofreram abusos sexuais, intimidação e, ao fim de dois anos, foram sumariamente transferidas para a aldeia dos seus inimigos históricos (... $)^{33}$

32 GAGNEBIN, Jeanne Marie. Lembrar, Escrever, Esquecer. São Paulo: H 34, 2006. p. 117.

33 COMISSÃO NACIONAL DA VERDADE, 2014, p. 222. 
Com a transferência para a aldeia dos Javaé, na llha do Bananal, os AváCanoeiro ${ }^{34}$ passam a viver sob o domínio de um grupo rival como cativos, em situação de marginalização constante. A transferência proporciona o aniquilamento das diferenças e disputas entre os grupos e interfere nas relações políticas ${ }^{35}$, demandando a construção de novas teias sociais.

Os Avá-Canoeiro, assim como os Parakanã, passam por um processo violento de deslocamentos, sendo sugados de seus territórios e introduzidos em outros em condição inferior a que viviam. Essa ação implica perdas, não somente do espaço concreto, mas culturais, de autonomia, o que demanda, por parte do grupo, uma intensa ação de reelaboração que incide diretamente nos modos de ser, viver e conceber o espaço. "(..) a desterritorialização desses povos, repentinamente retirados de seus territórios tradicionais (...) implicou em muitas perdas, sobretudo culturais, comprometendo por sua vez um processo de efetiva adaptação e reterritorialização (...) $)^{36}$, analisam os autores ao ser referirem aos povos deslocados para o Parque Indígena do Xingu.

Os grupos étnicos transformam-se a partir de processos de apropriação, descarte, reinterpretação dos discursos e contextos vivenciados na vida diária, portanto, a identidade não é algo dado ${ }^{37}$. mas sim um processo constante de tornarse a ser, todavia, nesses casos, esse processo se configura como extremamente violento e assimétrico, pois, os grupos étnicos são obrigados a reconfigurarem-se enquanto grupo a partir de espaços/territórios alheios, como foi, por exemplo, o caso dos Avá-Canoeiro

Orelatório da Comissão Nacional da Verdade (CNV) - Violação dos Direitos Humanos dos Povos Indígenas - apurou que, no período de 1946 a 1988, aproximadamente 8.350 indígenas foram mortos em diversas regiões do Brasil, incidindo essa prática deliberada de violência sobre diversas etnias. Somente a abertura da Perimetral Norte (BR-210), na década de 1970, atingiu aproximadamente

34 Para uma análise mais profícua da situação de extrema violência vivenciada pelos Avá-Canoeiro ver: RODRIGUES, Patrícia de Mendonça. Os Avá-Canoeiro do Araguaia e o tempo do cativeiro. Anuário Antropológico/2012-I, 2013: 83-137.

35 MENEZES, M. Lúcia Pires. Parque Indígena do Xingu: a construção de um território estatal. Campinas: Unicamp/Imprensa Oficial, 2000.

36 DEUS, J. A. Souza de; RODIGUES, L. Miranda; BARBOSA, L. de Deus. Processos de Desterritorialização e Reterritorialização de Sociedades Indígenas na Área Xinguana e Entorno-Amazônia Meridional/Brasil. In: Anais do Encuentro de Geógrafos da America Latina. Lima Peru, 2013. Disponível em: http://www.egal2013.pe/wp-content/uploads/2013/07/Tra_Jos\%C3\%A9-Ludimila-Liliane.pdf. Acesso em: 16 de abril de 2017. p. 9.

37 IBÁÑEZ, Jorge Larraín. Modernidade, Razón y Identidade em America Latina. Santiago: Andrés Bello, 1996. 
59 etnias, outras tantas foram impactadas pela construção da Transamazônica, BR174, BR-163, pela Usina Hidrelétrica de Tucuruí e tantos outros projetos.

- relatório da Comissão Nacional da Verdade caracteriza a Política Indigenista pós 1969 como um programa de etnocídio que visava eliminar os obstáculos aos interesses do Estado empregando o uso oficial de armas para fazer frente à resistência dos grupos indígenas considerados inimigos do programa de desenvolvimento empreendido pelo governo.

Ao quebrar o silêncio, os povos indígenas têm exposto suas narrativas, tão sombrias e ignóbeis quanto às demais que conhecemos sobre esse período da História do Brasil. Os militares usaram contra os povos indígenas um aparato bélico inimaginável que ia desde a distribuição de açúcar misturado com arsênio a metralhadoras, dinamites, helicópteros, e os presídios indígenas. Carvalho ${ }^{38}$ publica nos anexos do seu livro, "Waimiri-Atroari: a história que ainda não foi contada", cópia do ofício n 042/E2 do Comando Militar da Amazônia. Nele, são apresentadas orientações sobre a postura das guarnições do Exército com relação aos índios. Um dos itens do referido ofício determina a postura a ser assumida quando da visita dos índios ao posto. $\bigcirc$ ofício determina que "(...) caso haja visitas dos índios, realize pequenas demonstrações de força, mostrando aos mesmos os efeitos de uma rajada de metralhadora, de granadas defensivas e da destruição pelo uso da dinamite".

Diante desses indícios torna-se urgente repensarmos as narrativas produzidas acerca desse período da História do Brasil de forma a reconhecer que a Ditadura Militar agiu, assim como o fez contra os movimentos urbanos e rurais de resistência, contra as diferentes etnias indígenas que habitavam os espaços cobiçados por empresários e pelo próprio Estado.

\section{a construção da br-174, a resistência e a dizimação dos waimiri-atroari}

A construção da BR-174 interessava ao Estado Brasileiro e a diferentes setores empresariais, pois facilitaria o acesso às terras da região e a implementação de grandes projetos de mineração e de hidrelétricas. Assim, a tese da inevitabilidade da estrada se colocava para todos, inclusive para a FUNAI, que deveria agir a partir dessa certeza.

Com o início da construção da BR-174, em 1967, têm início a luta armada contra os Waimiri-Atroari, que só termina em 1977 com a inauguração da estrada e com toda a resistência indígena esmagada.

${ }^{38}$ CARVALHO, José P. F. de. Waimiri-Atroari: a história que ainda não foi contada. Brasília: 1982. p. 152. 
A construção da estrada cortando o território ancestral do grupo gerou resistência, apesar dos indígenas não saberem exatamente o que estava ocorrendo, pois não foram comunicados da construção. $\bigcirc$ movimento de resistência liderado por Maiká - líder, pajé e cantador - resultou na interrupção da construção da estrada entre os anos de 1968 e 1971. De acordo com informações do Relatório do Comitê da Verdade, a aldeia desse líder foi a primeira a ser atingida pela estrada, e, após várias tentativas frustradas de deter o avanço da estrada, ele resolveu mudar, construir uma nova aldeia que rapidamente foi alcançada pelas frentes de construção, havendo novo confronto ${ }^{39}$. Após esse confronto, uma nova migração foi realizada, indo Maiká com "sua gente" viver no Igarapé Monawa, afluente do rio Alalaú, onde morreu após um ataque aéreo realizado em sua aldeía.

cacique Maruaga aparece nos registros após a retomada da construção da estrada, já sob o comando do exército. A documentação apresenta indícios de que esse líder de várias aldeias Waimiri-Atroari foi responsável por um pequeno período de trégua entre índios e as frentes de trabalho.

A informação foi liberada ontem, pelo gabinete do General Bandeira de Melo, presidente da EUNAI, acrescentando que a contribuição do sertanista, Gillberto Pinto Figueiredo, mantendo-se em contato constante com o cacique Maruaga - chefe-geral das 15 aldeias - foi decisiva para o prosseguimento dos trabalhos. A companhia de Engenharia que está atuando na área, chegou à paralisar por duas vezes seus trabalhos, por temer o choque com índios, enquanto Gilberto prosseguia no contato com o grupo. $\bigcirc$ sertanista, que já vem atuando entre os Atroari-Waimiri desde a morte do Padre Calleri, conseguiu convencer o cacique Maroaga de que a estrada traria benefícios para o grupo ${ }^{40}$.

Outro líder que se destaca no movimento de resistência é o tuxaua Comprido. Esse liderou um ataque na região do Alalaú, após aproximadamente 33 índios serem mortos em uma aldeia em festa.

39 O Relatório do Comitê Estadual associa esse confronto relatado pelos indígenas com o massacre da Expedição do Padre Calliere, que ocorreu no ano de 1968.

40 CORREIO DA MANHÃ, 1972 Apud FILHO, Eduardo Gomes da Silva. Projetos de Desenvolvimento na Amazônia e a Resistência dos Waimiri-Atroari (1964-2014). Dissertação de Mestrado defendida na Universidade Federal do Amazonas, 2015. p. 86.

\footnotetext{
Wonfris, Maria Geralda simeida. Fndios e militares no século xx: a invisioilidade do caos humano nas fronteiras.

albuquerque: revista de história. val. 9, no 18. jul.-dez. de 2017. p. 65-84.
} 
No segundo semestre de 1974, Kramna Mudî acolhia o povo Kiña para uma festa tradicional. Já tinham chegado os visitantes do Camanaú e do Baixo Alalaú. $\bigcirc$ pessoal das aldeias do Norte ainda estava a caminho. A festa já estava começando com muita gente reunida. Pelo meío dia um ronco de avião ou helicóptero se aproximou. $\bigcirc$ pessoal saiu da maloca para ver. A criançada estava toda no pátio para ver. $O$ avião derramou como que um pó. Todos, menos um foram atingidos e morreram.

$\bigcirc$ tuxaua Comprido, com a sua gente vinha do Norte e ainda não chegara. Quando se aproximaram estranharam o silêncio. Aldeía em festa sempre está cheía de algazarra. Ao entrarem no pátio encontraram todos mortos, menos um. Morreram sem um sinal de violência no corpo. Dentro da maloca, nos girais, grande quantidade de carne moqueada, mostrando que tudo estava preparado para receber muita gente para a festa ${ }^{41}$

extermínio dessa aldeía inteira no Baixo Alalaú é registrado no Relatório do Comitê Estadual (2014) a partir de fragmentos produzidos pelos próprios índios durante as aulas do programa de alfabetização dos Schwade. Ação bem similar a anterior é narrada por Viana Womé Atroari à TV Brasil.

Foi assim tipo bomba, lá na aldeia. $\bigcirc$ índio que estava na aldeia não escapou ninguém. Ele veio no avião e de repente esquentou tudinho, aí morreu muita gente. Foi muita maldade na construção da BR-174. Aí veio muita gente e pessoal armado, assim, pessoal do Exército, isso eu vi. Eu sei que me lembro bem assim, tinha um avião assim um pouco de folha, assim, desenho de folha, assim, um pouco vermelho por baixo, só isso. Passou isso aí, morria rapidinho pessoa. Desse aí que nós via (17:47-18:37) ${ }^{42}$

documento destaca ainda que várias aldeias no igarapé Santo Antônio do Abonari, Baixo Alalaú e no Médio Alalaú desapareceram nesse período, evidenciando que a política genocida do estado militar estava atingindo seus objetivos: não deixar que o índio fosse obstáculo aos interesses do Estado.

\footnotetext{
${ }^{41}$ COMITÊ ESTADUAL, 2012, p. 15.

${ }^{42}$ COMITÊ ESTADUAL, 2012, p. 16.
} 
De acordo com Schwade ${ }^{43}$, algumas ações de resistência liderada por Tuxaua Comprido ocorreram após o massacre supracitado:

Um grupo de Kiña atacou três funcionários da FUNAI, João Dionísio do Norte, Paulo Ramos e Luiz Pereira Braga, que subiam - Rio Alalaú para abastecerem o Posto Alalaú II. Mataram os três e jogaram os corpos na altura da Travessia, local onde uma Umá (varadouro) atravessa o Alalaú, a aproximadamente seis quilômetros da aldeia chacinada. No dia seguinte, o tuxaua Comprido atacou o Posto Alalaút II, a aproximadamente $500 \mathrm{~m}$ da ponte do rio Alalaú, então, o ponto mais avançado da BR-17444.

ataque ao Posto Alalaú II, bem como aos funcionários da FUNAI no rio Alalaú é densamente descrito por Carvalho 45 sob o ponto de vista dos funcionários da FUNAI, todavia, em nenhum momento o ataque à aldeia Kramna Mudî, no qual 33 indígenas foram mortos, é relacionado como fator motivador da ação liderada por Comprido. Dar voz aos silenciados não é uma tarefa fácil, pois para tecer suas narrativas temos que nos debruçar sobre a documentação produzida, na maioria das vezes, por aqueles que querem o silêncio. As vozes dos subalternos encontramse submersas sob as vozes do Estado e da elite, são, portanto, "(..) voces bajas que quedan sumergidas por el ruido de los mandatos estatistas. Por esa razón no la oímos"46.

envolvimento dos indígenas no movimento de resistência se evidência não somente nos relatos narrados por sobreviventes, mas no censo realizado em 1983. Dos 332 sobreviventes, 216 eram crianças ou tinham menos de 20 anos, o que demonstra que a população adulta esteve diretamente envolvida nas ações de resistências, sendo, ainda, vitimada pelos ataques e emboscadas realizadas pelas frentes de construção da estrada.

${ }^{43}$ CIMI. 2000 Waimiri-Atroari desaparecidos durante a ditadura militar - 3. Entrevista com Egydio Schwade. 2011, p. 1. Disponível em: http://www.cimi.org. br/site/pt-br/?system=news\&action=read\&id=5552. Acesso em: 28 de junho de 2017.

${ }^{44}$ Idem.

45 CARVALHO, 1982.

${ }^{46}$ GUHA, Renajit. Las voces de La Historia y otros estúdios subalternos. Barcelona: Crítica, 2002. p. 20. 
A ação da população masculina, visando preservar a vida de crianças e mulheres, é narrada no episódio a seguir ${ }^{47}$

(...) Yanumá procurou reter o ataque, enquanto mulheres e crianças fugiam pelo caminho que conduzia a aldeia de Wanakta, localizada no Alto Río Camanaú. Mortalmente ferido, Yanumá ainda conseguiu alcançar a mulher com os filhos. Sentindo-se desfalecer recomendou a mulher que refugiasse na aldeia de Wanakta (... ${ }^{48 .}$

resultado dessa violência é registrado pelos professores Schwade, quando viviam na aldeia Yawara, no período em que desenvolveram o projeto de alfabetização.

As 31 (trinta e uma) pessoas da aldeia Yawara, ao tempo que ali foì desenvolvido esse primeiro processo de alfabetização (1985-1986). eram sobreviventes de quatro aldeias localizadas à margem direita do rio Alalaú, desaparecidas durante a abertura da rodovia BR-174. A pessoa mais velha não passava dos 40 anos. Todas as demais, acima de dez anos, eram órfãs, exceto duas irmãs, cuja mãe ainda vivia. Seus pais morreram na guerra genocida, durante a construção da rodovia. E as crianças de quatro a dez anos também eram órfãs de pai e mãe. Seus pais morreram de sarampo em 1981, abandonados pela EUNAI à beira da BR-174, no Km 28549.

Nesse período, os indígenas estiveram à "mercê" da própria sorte, pois as ações praticadas pela FUNAI em nenhum momento foram de apoio à causa indígena, ao contrário, objetivavam contribuir com a política de favorecimento de interesses dos não indígenas.

Embora seus nomes não constem nas listas oficiais de mortos, desaparecidos por resistirem ao regime militar, eles foram considerados empecilhos aos interesses de desenvolvimento e segurança nacional, sendo, inclusive, taxados de guerrilheiros, como consta no panfleto 50 escrito por ocasião da operação Atroaris.

${ }^{47}$ COMITÊ ESTADUAL, 2012, p.8.

48 Idem.

49 COMITÊ ESTADUAL, 2012, p. 9.

${ }^{50}$ Ibidem (p. 45-46). 


\section{0 que indicam as fontes?}

A partir da documentação consultada é possível afirmar que os WaimiriAtroari foram tratados como inimigos do Estado durante esse período, sendo vítimas do regime militar como qualquer outro segmento envolvido na resistência à ditadura.

Se de 1968 a 1971 a resistência indígena parou a construção da estrada, embora não tenha impedido a sua continuidade, nem alterado seu traçado, a retomada da obra significou a oficialização e a ampliação da violência cometida contra os indígenas.

A partir de 1974, por meio do Ofício n. 042, de 21 de novembro de 1974, que orienta os procedimentos para com os indígenas, a violência é oficializada e conta com o apoio da própria EUNAI.

E assim, naquela manhã de novembro, foi oficializada a guerra que desde há muito tempo existia contra os índios Waimiri-Atroari. Isso com o aval de funcionários da Funai, concordando em tudo que lhes fora dito e determinado pelo alto Comando do $2^{\circ}$ Grupamento de Engenharia e Construç̧ão ${ }^{51}$.

De acordo com Raimundo Pereira, em entrevista a Schwade ${ }^{52}$, após atravessarem o rio Alalaú, encontraram um grupo de índios e o Batalhão de Infantaria da Selva do Exército (BIS) os levou até a base, lá procedeu, conforme orientação, com rajadas de tiros "aberando os índios", sendo que, na sequência, os índios foram colocados em caçambas e transferidos para outra região, porém, não se sabe ao certo o que efetivamente acontecia.

O cenário que se configura a partir de então é o da ocupação e violência, "(..) aldeias inteiras foram massacradas em ações militares com a utilização de bombas, metralhadoras e produtos químicos ${ }^{\mathrm{n}} 3$. Homens e mulheres, crianças e idosos, ninguém era poupado nessa varredura da floresta, os "(..) Waimiri-Atroari tombaram no silêncio da mata, foram sutilmente enterrados e esquecidos no espaço

\footnotetext{
${ }^{51}$ CARVALHO, 1982, p. 158 Apud COMITÊ ESTADUAL, 2014, p. 82.

52 COMITÊ ESTADUAL, 2014, p. 37.

${ }^{53}$ COMITÊ ESTADUAL, 2014, p. 7.
} 
e no tempo"54, como afirma Apoena Meireles em entrevista à Folha de S. Paulo em 1975.

Em meio a um cenário de violência, os Waimiri-Atroari buscaram compreender, a seu modo, a ocupação do seu território ancestral pelos kamña - não índio - e resistir. Vários ataques foram realizados pelos indígenas durante o período de abertura da BR -174, interrompendo temporariamente a obra, mas não alterando seu curso. Ataque à missão do padre Calleri em 1968 e ao Posto Indígena Abonari em 1974, nos quais foram vitimados indígenas e não indígenas, evidenciam essa luta para pôr fim à ocupação.

Dos escombros da tragédia, as memórias emergem, rompem o silêncio que mantém as impunidades e evidencia a violência cometida contra os indígenas, e, ao mesmo tempo, lança luz sobre suas ações de resistência, pois é necessário que estes passem a figurar tanto nas estatísticas de vítimas da ditadura como nas narrativas produzidas acerca desse período, rompendo com a invisibilidade histórica dessas minorias étnicas.

processo de ocupação das terras habitadas pelos Waimiri-Atroari, consideradas pelo Estado como "vazio demográfico", ocorre ao longo de toda a história republicana e não se encerra com o fim da Ditadura, é um processo perene que tem sido extremamente prejudicial à existência autônoma desse povo.

Se, por um lado, constatamos que a violência ocorre sistematicamente, observamos, também, que o movimento de resistência se evidência em todos os momentos, embora, na maioria das vezes sejam descaracterizados, deslegitimados, favorecendo assim a construção de representações negativas acerca da índole, do caráter e do modo de vida desse povo. Esse processo, como ressalta Guha55, é próprio da ação da elite, responsável pela produção dos registros. Estes buscam retratar a ação dos subalternos de forma a torná-la espontânea, sem planejamento, descrevendo-os como bárbaros, excluindo-se, desse modo, o "rebelde" como sujeito consciente de sua própria história.

Nosso diálogo com as fontes oficiais e não oficiais ocorreu a partír da perspectiva de compreender esse processo violento a que os Waimiri-Atroari foram submetidos, porém, objetivando não reduzir a discussão a esse recorte, mas buscar a ação efetiva destes sujeitos subalternizados, subjugados, violentados, porém atuantes. Não se trata aqui de negar a violência a que foram submetidos, mas compreender para além dela, contribuindo, assim, para que os indígenas ocupem seu lugar no palco, mesmo que esse espaço seja o da tragédia. Uma tragédia que,

\section{${ }^{54}$ COMITÊ ESTADUAL, 2014, p. 88.}

${ }^{55}$ GUHA, 2002.

\footnotetext{
Morfika, Maria Geralda almeida. Indios e militares no século Xx: a invisibilidade do

caos humano nas fronteiras.

albuquerque: revista de história. vol. 9, no 18. jul.-dez. de 2017, p. 65-84.
} 


\section{4}

nesse caso, decorre simplesmente do fato de o grupo habitar uma região cobiçada pelas frentes de expansão, naquele momento liderado pelo Estado.

No movimento de resistência dos Waimiri-Atroari nos deparamos com três lideranças de destaque nos anos iniciais de construção da BR, os quais tiveram seus nomes registrados na documentação produzida: Maiká, Comprido e Maroagaa. A ação desses líderes, principalmente de Maroaga que sobreviveu à construção da BR, motivou a criação do movimento em apoio à causa Waimiri-Atroari.

A violação dos direitos indígenas ocorreu nas mais diferentes regiões do país, do Centro-Oeste ao Sudeste, do Nordeste ao Norte, atingindo dezenas de etnias. No processo de formação de uma memória nacional sobre o período da Ditadura Militar, os indígenas, mais uma vez, foram esquecidos, todavia, atualmente, torna-se oportuno revisitarmos esses espaços temporais e. de posse de novas bases epistêmicas, novas fontes, inserir estes sujeitos no processo histórico. 